TITLE:

\title{
Biogeographic variation in skull morphology across the Kra Isthmus in dusky leaf monkeys
}

$\operatorname{AUTHOR}(\mathrm{S}):$

Ito, Tsuyoshi; Koyabu, Daisuke

\section{CITATION:}

Ito, Tsuyoshi ... [et al]. Biogeographic variation in skull morphology across the Kra Isthmus in dusky leaf monkeys. Journal of Zoological Systematics and Evolutionary Research 2018, 56(4): 599-610

\section{ISSUE DATE:}

2018-11

URL:

http://hdl.handle.net/2433/243819

\section{RIGHT:}

This is the peer reviewed version of the following article: [Tsuyoshi Ito, Daisuke Koyabu. Biogeographic variation in skull morphology across the Kra Isthmus in dusky leaf monkeys. 'Journal of Zoological Systematics and Evolutionary

Research' 56(4), 599-610], which has been published in final form at https://doi.org/10.1111/jzs.12229. This article may be used for non-commercial purposes in accordance with Wiley Terms and Conditions for Use of Self-Archived Versions.: The full-text file will be made open to the public on 04 October 2019 in accordance with publisher's 'Terms and Conditions for Self-Archiving; ‘ こ論文は出版社版でありません。引用の際には出版社版をご確認ご利用くださし 。; This is not the published version. Please cite only the published version. 
Biogeographic variation in skull morphology across the Kra Isthmus in dusky leaf monkeys

Running title: Biogeographic variation in dusky leaf monkeys

Tsuyoshi Ito ${ }^{1}$, Daisuke Koyabu ${ }^{2}$

${ }^{1}$ Department of Evolution and Phylogeny, Primate Research Institute, Kyoto University, Inuyama, Aichi 484-8506, Japan

${ }^{2}$ The University Museum, The University of Tokyo, Hongo 7-3-1, Bunkyo-ku, Tokyo 113-0033, Japan

Corresponding author: Tsuyoshi Ito

E-mail: ito.tsuyoshi.3a@kyoto-u.ac.jp

Keywords: geometric morphometrics; Southeast Asia; Thai-Malay Peninsula 


\section{Abstract}

3

Despite the growing literature on the underlying factors of geographical phenotypic

4 variation, little is known about how and to what extent biogeographical barriers in Southeast

5 Asia have shaped morphological variation in primates. We aimed to investigate the

6 geographical variations in skull morphology in dusky leaf monkeys by decomposing them

7 into clinal (latitudinal), non-clinal spatial (discrete difference between regions north and

8 south of the Isthmus of Kra), and environment-related components. We applied geometric

9 morphometrics to measure 53 adult male specimens from 36 localities, covering the regions

10 both north and south of the Isthmus of Kra. A linear model was used to test the effects of

11 region (north vs. south of the Isthmus of Kra), latitude, and environmental factors

12 (temperature and rainfall) on the size and shape of skulls. A part of variation in skull shape

13 differed moderately between the regions in the north and south of the Isthmus of Kra, and

14 this difference cannot be explained by latitudinal and environmental factors. However, for

15 size and the majority of variations in shape, we detected limited contributions of region and

16 the two environmental factors. Shape differentiation that was unexplained by latitudinal and

17 environmental factors suggests that dusky leaf monkeys may have experienced a population

18 division due to habitat constriction around the Isthmus of Kra. However, this divergence

19 probably has been obscured by subsequent gene flow between populations after habitat 20 recovery. 


\section{Introduction}

Understanding the processes underlying biogeographic phenotypic diversity is one of

24 the major challenges in evolutionary biology. In particular, non-human primates have been intensively investigated as a model to understand the biogeographical patterns and diversification history of humans. To date, spatial distributions of size and other aspects of phenotype have been well described (e.g., Fooden \& Albrecht 1999; Frost, Marcus, Bookstein, Reddy, \& Delson 2003; Hamada, Watanabe, \& Iwamoto 1996; Rae, Hill, Hamada, \& Koppe 2003). With recent advances in the worldwide climatic database and biogeographic statistics, it has been increasingly recognized that both spatial and environmental factors (e.g., temperature and rainfall) are significant predictors of morphological variations among primates (e.g., Caceres et al. 2014; Cardini, Jansson, \& Elton 2007; Dunn, Cardini, \& Elton 2013). However, such recent studies have mostly targeted continental patterns. Little is known about how primate morphology varies biogeographically in Southeast Asia, an area composed of numerous peninsulas/islands and that is undoubtedly influenced by sea-level fluctuations.

The Isthmus of Kra (IOK; the narrowest part of the Thai-Malay peninsula, at approximately $10^{\circ} \mathrm{N}$ ) has been recognized as one of the key biogeographic boundaries for various taxa in Southeast Asia. Arguably, the IOK forms the boundary between the Sundaic and Indochinese biotas (Wallace 1876). It has long been believed that the Neogene seaways surrounding the IOK accounted for the formation of floral and faunal transitions in this region (Haq, Hardenbol, \& Vail 1987; Hughes, Round, \& Woodruff 2003; Woodruff 2003). However, recent paleoenvironmental studies have proposed that Neogene rises in sea level were not sufficient to bisect the Thai-Malay peninsula (Lisiecki \& Raymo 2005; Miller et al. 2005; Naish \& Wilson 2009). Accumulating biogeographic evidence supports this 
of the faunal population along the Thai peninsula; this compression, along with climatic zone transition, was responsible for the faunal transition (Hannah 2009; Hughes, Satasook, Bates, Bumrungsri, \& Jones 2011; Parnell 2013; Woodruff \& Turner 2009). Thus, the faunal transition in this region may have been historically formed by non-geophysical (i.e., ecological and climatic) factors, making the IOK distinct among known biogeographical boundaries.

Some species or pairs of closely related species of terrestrial vertebrates are distributed cross-boundary, and despite the absence of geophysical barriers, they are often considerably differentiated both genetically and morphologically between the regions north and south of the Thai-Malay peninsula (e.g., de Bruyn, Nugroho, Hossain, Wilson, \& Mather 2005; den Tex \& Leonard 2013; Endo, Hayashida, \& Fukuta 2007; Endo et al. 2000b; Hamada, Suryobroto, Goto, \& Malaivijitnond 2008; Hayashida et al. 2007; Luo et al. 2004; Tosi, Morales, \& Melnick 2002). Other taxa, however, show more complex biogeographical patterns. For example, southern populations show polymorphisms while northern ones do not [e.g., pelage color in stump-tailed macaques (Koyabu, Malaivijitnond, \& Hamada 2008), and skull morphology and cytotypes in tree shrews (Endo et al. 2000a; Hirai et al. 2002)]. In contrast, studies on long-tailed macaques with dense regional sampling have revealed that body size and relative tail length vary gradually along the peninsula, with no obvious discontinuous transition at the IOK (Fooden 2006; Fooden \& Albrecht 1999), following the patterns predicted by Bergmann's and Allen's rules. Other dense regional samplings have also shown that even when clear genetic and/or morphological subdivisions are observed, the transitional zone is not necessarily consistent with the IOK in various taxa (Bunlungsup,

69 Imai, Hamada, Matsudaira, \& Malaivijitnond 2017; Dejtaradol et al. 2016; Malaivijitnond et al. 2012; Patou et al. 2010). These findings suggest that although organisms were geographically isolated and differentiated between northern and southern regions at some 
point in the past, they could have been admixed and homogenized via gene flow, through developmental, and/or adaptive responses to current climatic gradient across the IOK, at least for these taxa.

Morphological evidence can provide important clues for biogeographical inferences by taking advantage of vast museum collections that enable dense regional sampling (McLean et al. 2016). However, the vestige of ancient population subdivisions, if any, can be obscured by recent gene flow and/or responses to current environmental conditions, which makes morphological data ambiguous in the case of attempts to interpret phylogeographical history. One solution to this dilemma is to statistically decompose morphological variations in order to reveal the concealed vestige. For example, statistically decomposing skull morphological variations into size and shape components and then testing the biogeographical patterns of each component has been demonstrated to be an effective approach (e.g., Cardini \& Elton 2009; Elton, Dunn, \& Cardini 2010; Frost et al. 2003). In theory, this is because skull shape is less liable to change than is its size, and it is therefore likely to represent the historical background rather than the current environment (Cardini \& Elton 2009). Further dissecting each morphological component into spatial and environment-related variations will aid interpretation of the phylogeographic history of a taxon (Cardini \& Elton 2009; Cardini et al. 2007).

The present study examines the geographic variations in skull morphology in dusky leaf monkeys (Trachypithecus obscurus, Reid 1837), which are distributed widely and across the IOK on the Thai-Malay peninsula (Figure 1; Brandon-Jones et al. 2004; Groves 2001). Considering the paleobiogeographical history of the IOK, we hypothesize that dusky leaf monkeys were divided into northern and southern populations due to habitat constriction during the Neogene. Such a geographical isolation, if any, should have caused morphological differentiation between the northern and southern populations; however, after land recovery, 
97 such differences may have been obscured by subsequent gene flow, developmental, and/or 98 adaptive responses to current climatic gradients. We tested this hypothesis by decomposing 99 craniometric variations into size and shape components and evaluating the influence of three

100 key factors (clinal, non-clinal, and environmental factors) on each component. If discrete 101 differences are detected between the northern and southern populations, and if these 102 differences can be explained neither by clinal (latitudinal) nor environmental factors, the 103 most probable scenario would be that the ancient geographical barrier around the IOK has

104 prevented gene flow and driven differentiation. In contrast, the absence of such discrete 105 differences would likely indicate that the two populations had not been divided into regions 106 north and south of the IOK or that they were completely admixed and homogenized after re107 connection; however, the two may be difficult to distinguish. Detection of the mosaics of 108 discrete and clinal variations independent of environmental factors would indicate a higher 109 probability of the isolation and re-connection scenario.

\section{Materials and methods}

The sample comprised 53 adult male specimens of dusky leaf monkeys from 36

112 localities (Appendix 1, Figure 1). Maturity was judged by full eruption of molars. Specimens

113 showing any pathological signs were excluded from this study. The specimens are currently

114 housed at the Natural History Museum (London, UK), the National Museum of Natural 115 History (Washington DC, USA), and the Lee Kong Chian Natural History Museum 116 (Singapore).

117 Sixty-seven 3D landmarks were acquired from the skulls using a Microscribe 3DX 118 digitizer (Appendix 2) by a single observer. The cranium and mandible were occluded and 119 firmly fused together by Pritt MULTI-FIX Haftpunkte clay (Henkel, Düsseldorf). Missing 120 landmarks on one side were estimated by mirroring those on the other side. Missing 
121 landmarks on midsagittal or bilaterally-missing ones were estimated by mapping weighted 122 averages from the complete dataset onto the missing specimen using the "Morpho" package 123 (Schlager 2017) in $\mathrm{R}$ statistical software (R Core Team 2017). After filling in missing 124 landmarks, generalized Procrustes analysis was performed to superimpose landmark 125 configurations using MorphoJ software (Klingenberg 2011). Centroid size was calculated as 126 the square root of the sum of squares of the distances of all landmarks from the centroid. The 127 natural logarithm of centroid size was used for size variable. Symmetrical shape components 128 were subjected to principal component (PC) analysis to summarize skull shape variations in 129 MorphoJ.

To partition the skull variation into clinal, non-clinal spatial, and environmental 131 components, multivariate linear regressions were conducted using “car” package (Fox \& 132 Weisberg 2011) in R. Size or shape, represented by each PC score, was separately used as 133 the response variable. Explanatory variables consisted of size (if response variable is PC 134 score), region, latitude, and two environmental variables, as follows. Region was defined as 135 the dummy variable, wherein the localities north of the IOK were coded as " 0 " and those 136 south of it as "1." Latitude was used to evaluate clinal spatial variation, because the 137 distribution of the dusty monkey populations stretches from the north to the south of the 138 Thai-Malay peninsula. Environmental variables consisted of annual mean temperature and 139 annual precipitation for the past 30 years (1970-2000), and were obtained from the 140 WorldClim database using the “raster” package (Robert 2016) in R (Figure 1). A stepwise 141 Akaike information criterion (AIC) was conducted to identify the best model (i.e., the best 142 combination of explanatory variables that appropriately predict a response variable) using 143 the "MuMIn” package (Kamil 2016) in R. If region was selected as an explanatory variable, 144 the relative level of support of each model was evaluated by the change in AIC ( $\triangle$ AIC). 145 Models with $\triangle \mathrm{AIC}$ values of $0-2$ provided substantial support, whereas $\triangle \mathrm{AIC}>4$ indicated 
146 considerably lower support compared with the best model (Burnham \& Anderson 2003).

147 We also evaluated the Procrustes coordinate data as it is (in place of PC scores), because

148 individual PC axes are not necessarily biologically meaningful. The symmetric shape

149 components were regressed onto the same set of explanatory variables using "geomorph"

150 package (Adams \& Otárola - Castillo 2013) in R. Residual randomization permutation

151 procedure was utilized for the test of significance (Collyer, Sekora, \& Adams 2015). Finally,

152 to evaluate phenetic relationships among individuals, a neighbor-joining tree (Saitou \& Nei

153 1987) was constructed based on the Procrustes distance matrix of the symmetric shape

154 components as well as the residuals from the regression of them on size (allometry-adjusted

155 symmetric shape components). For this, the "shapes” (Dryden 2017) and "ape” packages

156 (Paradis, Claude, \& Strimmer 2004) in R were used.

157 Prior to performing statistical analyses, outliers were detected based on Smirnov-

158 Grubbs test $(\mathrm{P}<0.05)$ and removed (three outliers were detected in the two environmental 159 variables, and an additional 0-2 outliers in the PCs). The data used in this study is available $160 \quad$ at Dryad (doi:10.5061/dryad.1989g0t).

The first 8 PCs accounted for more than half of the total variance in the model (Table

163 1), and their distance matrix was highly correlated with Procrustes distance matrix of 164 symmetric shape components ( $r \geq 0.90)$. Size was not influenced by latitude, region, or 165 annual mean temperature, whereas it was larger in localities with higher annual precipitation. 166 Most major shape variables (PCs) were also independent of latitude or simply exhibited 167 latitudinal cline without significant differentiation between the regions north and south of the 168 IOK. For example, PC1 was slightly, but not significantly, explained only by annual mean 169 temperature. PC2 and PC6 scores gradually increased or decreased with increasing latitude, 
170 and no gap was observed at the IOK (Table 1; Figure 2). Only for PC4 was the model greatly

171 improved by incorporating region as an explanatory variable (Appendix 3), wherein PC4

172 scores were significantly smaller in the northern than in the southern region of the IOK. This

173 indicated that the face was relatively shorter, the anterior portion of the mandible was more

174 robust, and the inferior margin of the mandible was wider in the region north of the IOK than

175 in the south (Figure 3). PC8 scores were larger in the north than were expected by a latitudinal

176 cline, but this effect was tentative, as indicated by $\Delta \mathrm{AIC}$ (Appendix 3; Figure 2). For the test

177 using the Procrustes coordinate data as response variable, regional difference was detected,

178 but this difference disappeared in the full model that takes into account for the effects of

179 latitudinal and two environmental factors (Table 2). A neighbor-joining phenogram also did 180 not show clear clusters of northern and southern populations (Figure 4).

\section{Discussion}

The present study tested the hypothesis that the vestige of population subdivision is preserved in shape components, which are hidden under major variations in environmentsensitive morphological characters. For this purpose, we first decomposed skull variations into size and shape components, and then assessed the relative contributions of the ancient biogeographical barrier at the IOK and other factors to each of their variations.

Size was not significantly correlated with latitude, region (north vs. south of the IOK), nor annual mean temperature. However, it was significantly larger in the localities with higher annual precipitation. Whereas mammals in temperate or cold environments often show latitudinal size cline or negative correlation with temperature as predicted by

191 Bergmann's rule (Ito, Nishimura, \& Takai 2014), it is known that size variation is more highly correlated to annual precipitation than to temperature in the tropics (Capellini \& Gosling 2007; Cardini et al. 2007; Dunbar 1990). Such size variation in the tropics is considered to 
194 be a consequence of a response to the primary productivity of plants, and hence food 195 availability, which is largely influenced by rainfall (Cardini, Dunn, O'Higgins, \& Elton 2013). 196 The present finding in dusky leaf monkeys is congruent with these previous findings. On the 197 other hand, most shape components were virtually independent from the environmental 198 factors examined (annual mean temperature and annual precipitation) or simply showed a 199 latitudinal cline with no gap at the IOK. This indicates that observed variations in skull shape 200 do not reflect responses to current environmental conditions nor ancient genetic isolations. 201 Alternatively, they likely reflect gene flow among populations and/or other unknown factors.

202 The star-shaped phenogram (Figure 3) and no significant regional difference in the test of 203 Procrustes coordinate data also supports the regional homogeneity of this species. A part of 204 shape variation (only PC4) was differentiated between the regions south and north of the 205 IOK. As this discrete difference was not explained by latitudinal or environmental factors, 206 this could be a result of ancient genetic isolation. Since this region likely had no geophysical 207 barrier in the Neogene or later (Lisiecki \& Raymo 2005; Miller et al. 2005; Naish \& Wilson 208 2009), it seems that the rise in sea level may have caused a habitat compression around the 209 IOK, and thus genetic isolation between northern and southern populations (see Woodruff \& 210 Turner 2009). Thus, there might have been ancient genetic isolation influencing on the north211 south differentiation in the skulls of dusky leaf monkeys, but the differences probably have 212 been much blurred by subsequent substantial gene flow after the recovery of habitat 213 connection.

214 For organisms capable of relatively wide dispersals, diverged lineages can be easily 215 admixed, and genetic pools are often homogenized across the IOK (see Bunlungsup et al. 216 2017; Osada et al. 2010). As with the skull shape of dusky leaf monkeys, the pelage color 217 variations found in stump-tailed macaques also suggest such a history of isolation and re218 connection (Koyabu et al. 2008). In contrast, in some primate taxa from the Malay Peninsula, 
219 populations North and South of the IOK are even assigned into species-level differences. For example, pig-tailed macaques are divided into two species, and the boundary between the two is assumed to be located around the Surat Thani-Krabi depression, which is just south of the IOK (Malaivijitnond et al. 2012). The northern and southern species of pig-tailed macaques are dissimilar on a number of morphological characters such as facial length and sexual swelling patterns (Gippoliti 2001). The Bengal slow loris, which is distributed north of the IOK, is considerably different from its southern relative, that is the Sunda slow loris, in skull morphology and peleage color (Nekaris \& Jaffe 2007; Nekaris, Blackham, \& Nijman 2008; Ravosa 1998). Such a heterogeneity in the degree of admixture and morphological differentiations among taxa would be of great research interest, and may be caused by the differences in responsiveness to fluctuating habitat compressions. In conclusion, we add dusky leaf monkeys as another example of likely having experienced an ancient genetic isolation followed by substantial gene flow, although the impact and role of the IOK in shaping biogeographic variations in Southeast Asia is still disputed. Future studies are expected to elucidate the mechanisms of the maintenance of morphological differences in some specific taxa as well as the consequences of genetic admixture around the IOK.

\section{Acknowledgements}

We thank Mikiko Tanaka for her help with data preparation. We thank Kelvin Lim of Lee Kong Chian Natural History Museum for his kind care during the observations. We also thank Elisabeth Haring and anonymous reviewers for their constructive comments that greatly improved this paper. This study was funded by the Keihanshin Consortium for

240 Fostering the Next Generation of Global Leaders in Research (K-CONNEX) (to T.I.) and 241 JSPS Grants-in-Aid for Scientific Research (Grant 17K15195 to T.I. and 26711023 to D.K.). 
244 Adams, D. C. \& Otárola-Castillo, E. (2013). Geomorph: An R package for the collection and analysis of geometric morphometric shape data. Methods in Ecology and Evolution, 4, 393-399.

Brandon-Jones, D., Eudey, A. A., Geissmann, T., Groves, C. P., Melnick, D. J., Morales, J. C., Shekelle, M., \& Stewart, C. B. (2004). Asian primate classification. International Journal of Primatology, 25, 97-164.

250

251

252

253

254

255

256

257

258

259

260

261

262

263

264

265

266

Bunlungsup, S., Imai, H., Hamada, Y., Matsudaira, K., \& Malaivijitnond, S. (2017). Mitochondrial DNA and two Y-chromosome genes of common long-tailed macaques (Macaca fascicularis fascicularis) throughout Thailand and vicinity. American Journal of Primatology, 79, e22596

Burnham, K. P. \& Anderson, D. R. (2003). Model selection and multimodel inference: a practical information-theoretic approach. New York: Springer.

Caceres, N., Meloro, C., Carotenuto, F., Passaro, F., Sponchiado, J., Melo, G. L., \& Raia, P. (2014). Ecogeographical variation in skull shape of capuchin monkeys. Journal of Biogeography, 41, 501-512.

Capellini, I. \& Gosling, L. M. (2007). Habitat primary production and the evolution of body size within the hartebeest clade. Biological Journal of the Linnean Society, 92, 431-440.

Cardini, A., Dunn, J., O'Higgins, P., \& Elton, S. (2013). Clines in Africa: does size vary in the same way among widespread sub-Saharan monkeys? Journal of Biogeography, 40, 370381.

Cardini, A. \& Elton, S. (2009). Geographical and taxonomic influences on cranial variation in red colobus monkeys (Primates, Colobinae): introducing a new approach to 'morph' monkeys. Global Ecology and Biogeography, 18, 243-263. 
267 Cardini, A., Jansson, A.-U., \& Elton, S. (2007). A geometric morphometric approach to the 268 study of ecogeographical and clinical variation in vervet monkeys. Journal of Biogeography, 34, 1663-1678.

270

Collyer, M. L., Sekora, D. J., \& Adams, D. C. (2015). A method for analysis of phenotypic change for phenotypes described by high-dimensional data. Heredity, 115, 357-365.

272

de Bruyn, M., Nugroho, E., Hossain, M. M., Wilson, J. C., \& Mather, P. B. (2005). Phylogeographic evidence for the existence of an ancient biogeographic barrier: the Isthmus of Kra Seaway. Heredity, 94, 370-378.

275

276

277

278

279

280

281

282

283

284

285

286

287

288

289

290

Dejtaradol, A., Renner, S. C., Karapan, S., Bates, P. J. J., Moyle, R. G., \& Päckert, M. (2016). Indochinese-Sundaic faunal transition and phylogeographical divides north of the Isthmus of Kra in Southeast Asian Bulbuls (Aves: Pycnonotidae). Journal of Biogeography, 43, 471-483.

den Tex, R. J. \& Leonard, J. A. (2013). A molecular phylogeny of Asian barbets: speciation and extinction in the tropics. Molecular Phylogenetics and Evolution, 68, 1-13.

Dryden, I. L. (2017). shapes: Statistical Shape Analysis. R package version 1.2.0. Retrieved from https://cran.r-project.org/web/packages/shapes/index.html

Dunbar, R. I. M. (1990). Environmental determinants of intraspecific variation in body-weight in baboons (Papio spp). Journal of Zoology, 220, 157-169.

Dunn, J., Cardini, A., \& Elton, S. (2013). Biogeographic variation in the baboon: dissecting the cline. Journal of Anatomy, 223, 337-352.

Elton, S., Dunn, J., \& Cardini, A. (2010). Size variation facilitates population divergence but does not explain it all: an example study from a widespread African monkey. Biological Journal of the Linnean Society, 101, 823-843.

Endo, H., Hayashi, Y., Rerkamnuaychoke, W., Nadee, N., Nabhitabhata, J., Kawamoto, Y., 
291

292

293

294

295

296

297

298

299

300

301

302

303

304

305

306

307

308

309

310

311

312

313

314

Hirai, H., Kimura, J., Nishida, T., \& Yamada, J. (2000a). Sympatric distribution of the two morphological types of the common tree shrew in Hat-Yai Districts (South Thailand). Journal of Veterinary Medical Science, 62, 759-761.

Endo, H., Hayashida, A., \& Fukuta, K. (2007). Multivariate analyses of the skull size and shape in the five geographical populations of the lesser false vampire. Mammal Study, 32, 2331.

Endo, H., Nishiumi, I., Hayashi, Y., Rashdi, A. B. M., Nadee, N., Nabhitabhata, J., Kawamoto, Y., Kimura, J., Nishida, T., \& Yamada, J. (2000b). Multivariate analysis in skull osteometry of the common tree shrew from both sides of the Isthmus of Kra in southern Thailand. Journal of Veterinary Medical Science, 62, 375-378.

Fooden, J. (2006). Comparative review of fascicularis-group species of macaques (Primates: Macaca). Fieldiana Zoology, 107, 1-44.

Fooden, J. \& Albrecht, G. H. (1999). Tail-length evolution in fascicularis-group macaques (Cercopithecidae: Macaca). International Journal of Primatology, 20, 431-440.

Fox, J. \& Weisberg, S. (2011). An R Companion to Applied Regression. (Second edn.). Thousand Oaks CA: Sage.

Frost, S. R., Marcus, L. F., Bookstein, F. L., Reddy, D. P., \& Delson, E. (2003). Cranial allometry, phylogeography, and systematics of large-bodied papionins (primates: Cercopithecinae) inferred from geometric morphometric analysis of landmark data. The Anatomical Record Part A: Discoveries in Molecular, Cellular, and Evolutionary Biology, 275A, 1048-1072.

Gippoliti, S. (2001). Notes on the taxonomy of Macaca nemestrina leonina Blyth, 1863 (Primates: Cercopithecidae). Hystrix, the Italian Journal of Mammalogy, 12, 51-54.

Groves, C. P. (2001). Primate taxonomy. Washington DC: Smithonian Institution Press. 
315 Hamada, Y., Suryobroto, B., Goto, S., \& Malaivijitnond, S. (2008). Morphological and body color variation in Thai Macaca fascicularis fascicularis north and south of the Isthmus of Kra. International Journal of Primatology, 29, 1271-1294.

318

319

320

321

322

323

324

325

326

327

328

329

330

331

332

333

334

335

336

337

338

Hamada, Y., Watanabe, T., \& Iwamoto, M. (1996). Morphological variations among local populations of Japanese macaque (Macaca fuscata). In T. Shotake \& K. Wada (Eds.), Variations in the Asian macaques (pp. 97-115). Tokyo: Tokyo University Press.

Hannah, L. (2009). New insights on a classic topic: The biogeography of Southeast-Asian mammals. Frontiers of Biogeography, 1, 8-10.

Haq, B. U., Hardenbol, J., \& Vail, P. R. (1987). Chronology of fluctuating sea levels since the Triassic. Science, 235, 1156-1167.

Hayashida, A., Endo, H., Sasaki, M., Oshida, T., Kimura, J., Waengsothorn, S., Kitamura, N., \& Yamada, J. (2007). Geographical variation in skull morphology of gray-bellied squirrel Callosciurus caniceps. Journal of Veterinary Medical Science, 69, 149-157.

Hirai, H., Hirai, Y., Kawamoto, Y., Endo, H., Kimura, J., \& Rerkamnuaychoke, W. (2002). Cytogenetic differentiation of two sympatric tree shrew taxa found in the southern part of the Isthmus of Kra. Chromosome Research, 10, 313-327.

Hughes, A. C., Satasook, C., Bates, P. J., Bumrungsri, S., \& Jones, G. (2011). Explaining the causes of the zoogeographic transition around the Isthmus of Kra: using bats as a case study. Journal of Biogeography, 38, 2362-2372.

Hughes, J. B., Round, P. D., \& Woodruff, D. S. (2003). The Indochinese-Sundaic faunal transition at the Isthmus of Kra: an analysis of resident forest bird species distributions. Journal of Biogeography, 30, 569-580.

Ito, T., Nishimura, T., \& Takai, M. (2014). Ecogeographical and phylogenetic effects on craniofacial variation in macaques. American Journal of Physical Anthropology, 154, 27- 
41.

340 Kamil, B. (2016). MuMIn: Multi-Model Inference. R package version 1.15.6. Retrieved from https://cran.r-project.org/web/packages/MuMIn/index.html

Klingenberg, C. R. (2011). MorphoJ: an integrated software package for geometric morphometrics. Molecular Ecology Resources, 11, 353-357.

Koyabu, D. B., Malaivijitnond, S., \& Hamada, Y. (2008). Pelage color variation of Macaca arctoides and its evolutionary implications. International Journal of Primatology, 29, 531-541.

Lisiecki, L. E. \& Raymo, M. E. (2005). A Pliocene-Pleistocene stack of 57 globally distributed benthic $\delta 180$ records. Paleoceanography, 20, PA1003.

Luo, S.-J., Kim, J.-H., Johnson, W. E., Van Der Walt, J., Martenson, J., Yuhki, N., Miquelle, D. G., Uphyrkina, O., Goodrich, J. M., \& Quigley, H. B. (2004). Phylogeography and genetic ancestry of tigers (Panthera tigris). PLoS Biology, 2, e442.

352

353

354

355

356

357

358

359

360

361

Malaivijitnond, S., Arsaithamkul, V., Tanaka, H., Pomchote, P., Jaroenporn, S., Suryobroto, B., \& Hamada, Y. (2012). Boundary zone between northern and southern pig-tailed macaques and their morphological differences. Primates, 53, 377-389.

McLean, B. S., Bell, K. C., Dunnum, J. L., Abrahamson, B., Colella, J. P., Deardorff, E. R., Weber, J. A., Jones, A. K., Salazar-Miralles, F., \& Cook, J. A. (2016). Natural history collections-based research: progress, promise, and best practices. Journal of Mammalogy, 97, 287-297.

Miller, K. G., Kominz, M. A., Browning, J. V., Wright, J. D., Mountain, G. S., Katz, M. E., Sugarman, P. J., Cramer, B. S., Christie-Blick, N., \& Pekar, S. F. (2005). The Phanerozoic record of global sea-level change. Science, 310, 1293-1298. 
363

364

365

366

367

368

369

370

371

372

373

374

375

376

377

378

379

380

381

382

383

384

385

386

eustatic sea-level fluctuations from the New Zealand shallow-marine sediment record. Philosophical Transactions of the Royal Society A: Mathematical, Physical and Engineering Sciences, 367, 169-187.

Nekaris, K. \& Jaffe, S. (2007). Unexpected diversity of slow lorises (Nycticebus spp.) within the Javan pet trade implications for slow loris taxonomy. Contributions to Zoology, 76.

Nekaris, K. A. I., Blackham, G. V., \& Nijman, V. (2008). Conservation implications of low encounter rates of five nocturnal primate species (Nycticebus spp.) in Asia. Biodiversity and Conservation, 17, 733-747.

Osada, N., Uno, Y., Mineta, K., Kameoka, Y., Takahashi, I., \& Terao, K. (2010). Ancient genome-wide admixture extends beyond the current hybrid zone between Macaca fascicularis and M. mulatta. Molecular Ecology, 19, 2884-2895.

Paradis, E., Claude, J., \& Strimmer, K. (2004). APE: analyses of phylogenetics and evolution in R language. Bioinformatics, 20, 289-290.

Parnell, J. (2013). The biogeography of the Isthmus of Kra region: a review. Nordic Journal of Botany, 31, 001-015.

Patou, M.-L., Wilting, A., Gaubert, P., Esselstyn, J. A., Cruaud, C., Jennings, A. P., Fickel, J., \& Veron, G. (2010). Evolutionary history of the Paradoxurus palm civets - a new model for Asian biogeography. Journal of Biogeography, 37, 2077-2097.

R Core Team (2017). R: A language and environment for statistical computing. $\mathrm{R}$ foundation for Statistical Computing, Vienna.

Rae, T. C., Hill, R. A., Hamada, Y., \& Koppe, T. (2003). Clinical variation of sinus volume in Japanese macaques (Macaca fuscata). American Journal of Primatology, 59, 153-158.

Ravosa, M. J. (1998). Cranial allometry and geographic variation in slow lorises (Nycticebus). American Journal of Primatology, 45, 225-243. 
387

388

389

390

391

392

393

394

395

396

397

398

399

400

401

402

403

404

405

406

407

Robert, J. H. (2016). raster: Geographic Data Analysis and Modeling. R package version 2.58. Retrieved from https://cran.r-project.org/web/packages/raster/index.html

Saitou, N. \& Nei, M. (1987). The neighbor-joining method: a new method for reconstructing phylogenetic trees. Molecular Biology and Evolution, 4, 406-425.

Schlager, S. (2017). Morpho and Rvcg - Shape Analysis in R. In G. Zheng, S. Li, \& G. Szekely (Eds.), Statistical Shape and Deformation Analysis: Methods, Implementation and Applications (pp. 217-256). San Diego: Academic Press.

Tosi, A. J., Morales, J. C., \& Melnick, D. J. (2002). Y-chromosome and mitochondrial markers in Macaca fascicularis indicate introgression with Indochinese M. mulatta and a biogeographic barrier in the isthmus of Kra. International Journal of Primatology, 23, 161-178.

Wallace, A. R. (1876). The geographical distribution of animals: with a study of the relations of living and extinct faunas as elucidating the past changes of the earth's surface. London: Macmillan.

Woodruff, D. S. (2003). Neogene marine transgressions, palaeogeography and biogeographic transitions on the Thai-Malay Peninsula. Journal of Biogeography, 30, 551-567.

Woodruff, D. S. \& Turner, L. M. (2009). The Indochinese-Sundaic zoogeographic transition: a description and analysis of terrestrial mammal species distributions. Journal of Biogeography, 36, 803-821. 
409 Figure 1. Thirty-six localities of skull samples (black circles). Map is color-coded by (a) the distribution of Trachypithecus obscurus (red mesh; the IUCN Red List of Threatened Species, version 2016-3);

(b) annual mean temperature $\left({ }^{\circ} \mathrm{C} \times 10\right)$; and (c) annual precipitation (mm).

413 Figure 2. Biogeographic variations in skull shape as indicated by principal components (PCs).

(a) PC2; solid line indicates OLS regression line for total samples. (b) PC4; solid and dashed lines indicate median, and first and third quartiles, respectively, which are calculated separately for regions north and south of the IOK. (c) PC6; solid line indicates OLS regression line for total samples. (d) PC8; dotted line indicates OLS regression line for localities south of the IOK. Open circles indicate individuals originating from south of the IOK, and gray-filled ones indicate those from the north.

Figure 3. Shape changes along principal component (PC) axes: (a) PC2; (b) PC4; (c) PC6; and (d) PC8. Wireframes and points indicate dorsal (left) and lateral (right) views of skulls. Thin lines and open circles denote mean shape, while dark lines and filled circles denote positive extreme along each PC axis (+3 standard deviations).

424 Figure 4. Neighbor-joining phenogram based on Procrustes distances of skull shape: (a) the raw symmetric shape component; (b) the residuals from the regression of symmetric component on size. Open circles indicate individuals originating from south of the IOK, and gray-filled ones indicate those from the north. 
Tables

429

Table 1. Summary of PCA and the best model.

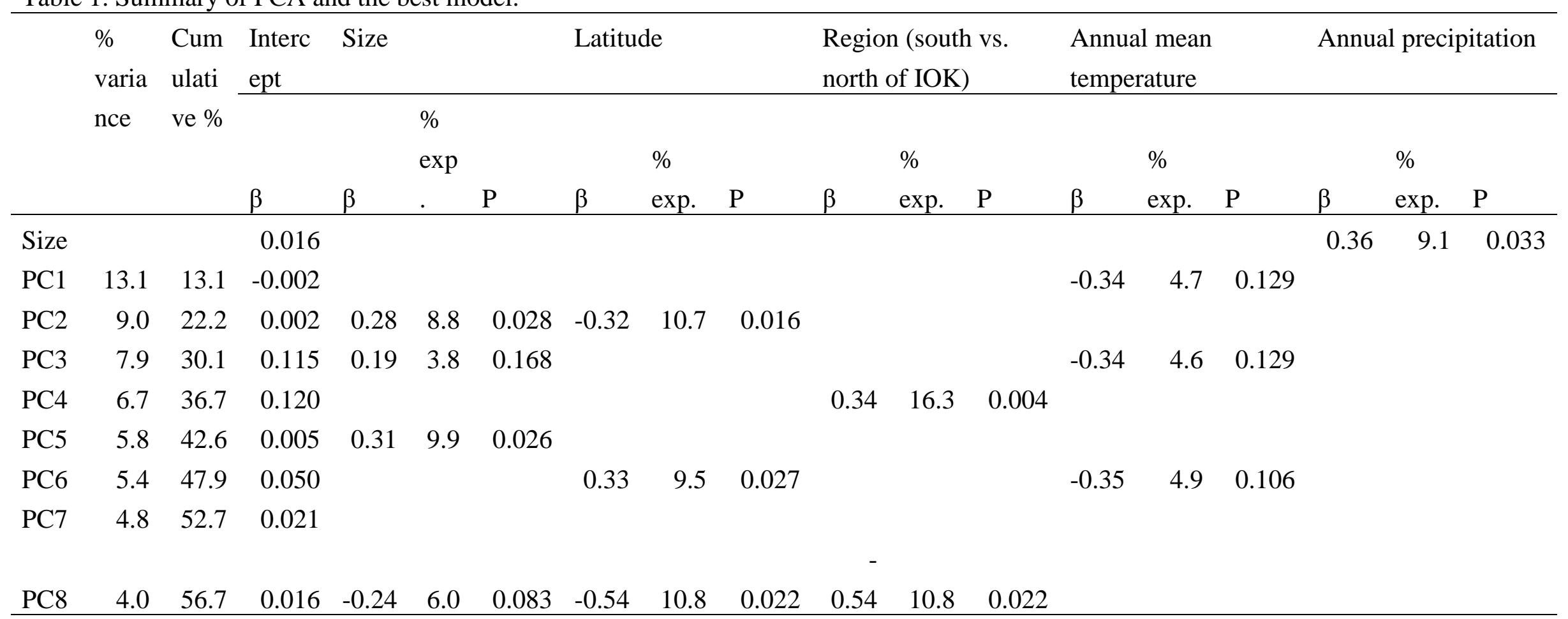

$\beta$, standardized partial regression coefficient; \% exp., the percentage of which a response variable is explained by an explanatory variable (based on Type II ANOVA).

The total number of tests we performed are 14 (size and PC1-13); the results of PC9-13 are not shown. When Bonferroni adjusted, no effects are significant, but the effect of region on PC4 is close to significance $(\mathrm{P}=0.056)$. 
Table 2. Results of Procrustes regression of skull shape.

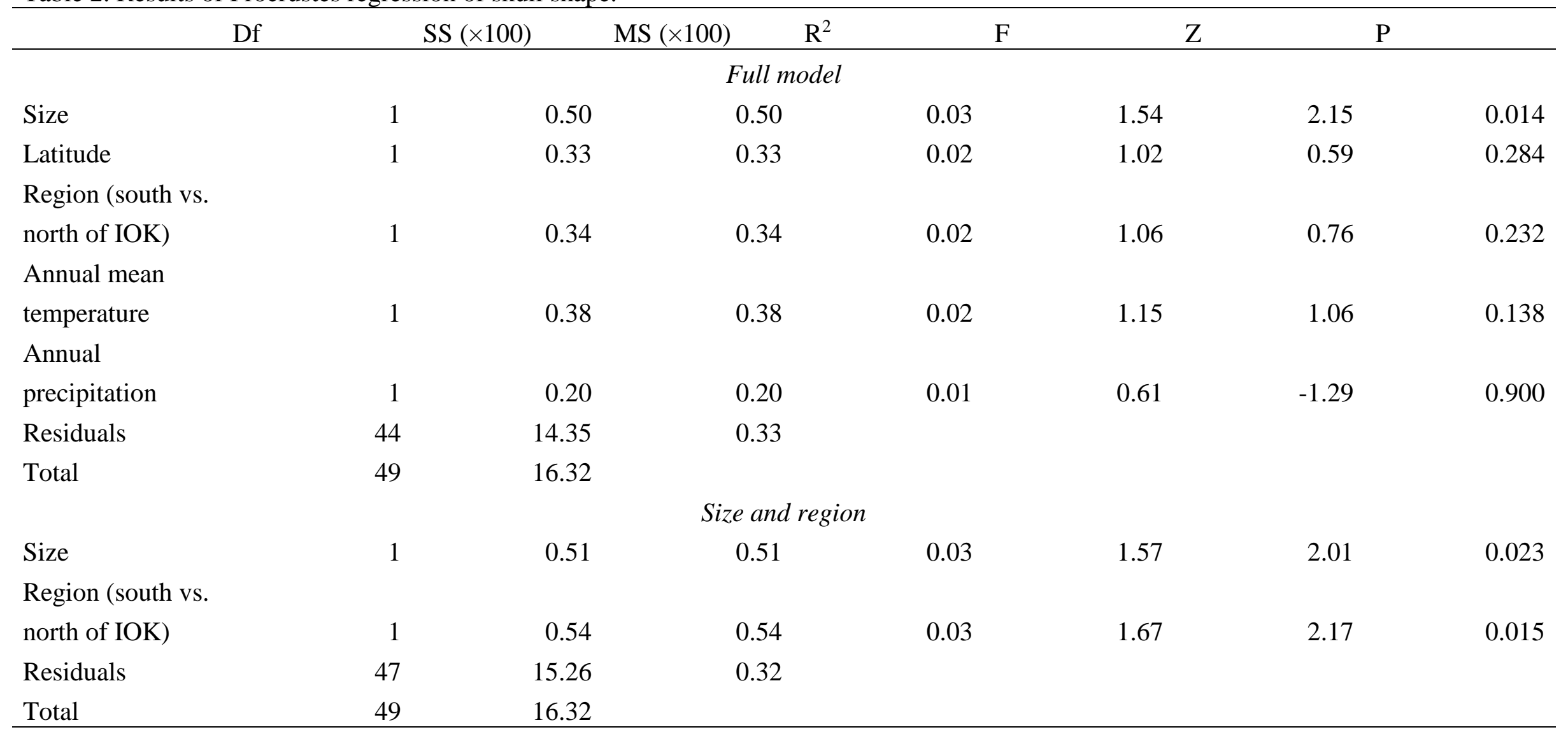


Appendix 1. Specimens used in this study.

\begin{tabular}{|c|c|c|c|}
\hline ID & Storage $^{\dagger}$ & Locality & Remarks \\
\hline 104444 & NMNH & Malaysia (no detailed info) & \\
\hline 112709 & NMNH & 2'18"N 103'17'"'E, Johor, Malaysia & \\
\hline 115497 & NMNH & 2'50"N 103'14"E, Rompin River, Pahang, Malaysia & \\
\hline 115498 & NMNH & 2'50"N 103'14"E, Rompin River, Pahang, Malaysia & \\
\hline 124113 & NMNH & 12'40"N 98'56"E, Tanintharyi, Burma & \\
\hline 124177 & NMNH & 12'40"N 98'56"E, Tanintharyi, Burma & \\
\hline 14.12.8.27 & NHM & 10'09"N, 98'36"E, Bankachon, S Tenasserim, Burma & \\
\hline 14.12.8.27a & NHM & 10'09"N, 98'36"E, Bankachon, S Tenasserim, Burma & \\
\hline 14.12.8.27b & NHM & 12'07"N, 99'03"E, Banlaw, Great Tenasserim river, Burma & \\
\hline 14.12.8.27c & NHM & 8'12"N, 99'43"E, Khao Wang, Peninsular Siam & \\
\hline 1980.161 & NHM & 12'30"N, 98'22"E, King Island, Mergui, Burma & Island \\
\hline 3.2.6.5 & NHM & 6'50" N, 101'20"E, Pattani, Siam & \\
\hline 4.438 & LKCNHM & 6'35"N, 99'40E, Waw, Telok, Pulau Terutao, Thailand & Island \\
\hline 4.448 & LKCNHM & 8'06"N 98'52"E Ban Nong Kok, Krabi, Thai & \\
\hline 4.45 & LKCNHM & 8'06"N 98'52"E Ban Nong Kok, Krabi, Thai & \\
\hline 4.455 & LKCNHM & 7'56"N 98'35"E, Yao Yai, Ko, Phangnga, Thailand & Island \\
\hline 4.46 & LKCNHM & 5'27"N 100'12"E, Bahang, Telok, Pulau Pinang, W Malaysia & Island \\
\hline 4.463 & LKCNHM & 5'27"N 100'12"E, Bahang, Telok, Pulau Pinang, W Malaysia & Island \\
\hline 4.465 & LKCNHM & 6'21"N 101'50"E, Ban Nara, Pattani, Thailand & \\
\hline 4.466 & LKCNHM & 6'21"N 101'50"E, Ban Nara, Pattani, Thailand & \\
\hline 4.469 & LKCNHM & 6'21"N 101'50"E, Ban Nara, Pattani, Thailand & \\
\hline
\end{tabular}


4.47

4.477

\subsection{8}

4.479

4.48

4.481

4.482

4.485

4.487

4.488

4.49

4.495

4.498

4.5

4.501

4.503

4.507

4.509

4.511

4.514

4.522

4.525

4.527

4.529

LKCNHM 6'21"N 101'50"E, Ban Nara, Pattani, Thailand

LKCNHM 6'39"N, 100'11"E, Pelarit, Malay, Peris

LKCNHM 6'39"N, 100'11"E, Pelarit, Malay, Peris

LKCNHM 4'53"N 100'45"E, Tea Garden, Larut Hills, West Malay, Perak

LKCNHM 8'06"N 98'52"E Ban Nong Kok, Krabi, Thai

LKCNHM 4'19"N, 100'34"E, Tanjong Hantu, Perak, Dinding, Malay

LKCNHM 3'44"N 101'14"E, Changkat Mentri, Sungei Bernam, Perka, W Malay

LKCNHM 4'45"N 100'45"E, Gantang, Bukit, Perak, W Malay

LKCNHM 4'59"N 103'07"E, Bukit Jong, W Malay, Trengganau

LKCNHM 4'59"N 103'07"E, Bukit Jong, W Malay, Trengganau

LKCNHM 4'01"N 102'18"E, Kuala Tembeling, Pahanag, W Malay

LKCNHM 3'40"N 101'45' E, Semangko Pass, Selangor, W Malay

LKCNHM 3'14"N 101'20"E, Bukit Chereka Klang, Jeram, Selangor, W malaysia

LKCNHM 3'19"N 101'46"E, Genting Bidai, Selangor, W Malay

LKCNHM 2'50"N 102'00"E, Bukit Tangga, Negeri Sembilan, W Malay

LKCNHM 2'24"N 101'52"E, Keramat Tanjung Tuan, Negeri Sembilan

LKCNHM 2'17"N 102'15"E, Nylas, W Malasia, Malaca

LKCNHM 2'17"N 102'15"E, Nylas, W Malasia, Malaca

LKCNHM 1'25N, 104'05"E, Si Karang, Johor, W Malay

LKCNHM 1'31"N 103'35" E, Tebrau, Johor, W Malay

LKCNHM 11'49"N 99'45"E, Prachuap Khiri Khan, Thailand

LKCNHM 10'28"N, 98' 55"E, Ban Tha San, Chumphon, Thailand

LKCNHM 5'54"N 102'45"E, Perhentian Besar Island, Pulau, Trengganau, W Malaysia

Island

LKCNHM 5'54"N 102'45"E, Perhentian Besar Island, Pulau, Trengganau, W Malaysia

Island 


\begin{tabular}{lll}
55.1534 & NHM & 3'40"N, 101'45"E, Semangko Pass, Selangorpahang Boundary, Malay \\
55.1535 & NHM & 3'18"N, 101'49" E, Genting Bidai, Selangor, Malay \\
55.154 & NHM & 4'19"N, 100'34"E, Tanjong Hantu, Perak, Dinding, Malay \\
55.1542 & NHM & 6'39"N, 100'11"E, Pelarit, Perlis, N Malay Pennisula., Malay \\
71.722 & NHM & 4'29'N, 100'55"E, Changkat Cheko, Parit, Malay \\
71.734 & NHM & 5'02"N, 100'39"E, Bukit Merah, Perak, Malay \\
71.735 & NHM & 5'02"N, 100'39"E, Bukit Merah, Perak, Malay, 1800ft \\
71.749 & NHM & 3'51'30''N, 102'11"25"'E, Mt. Benom, Pahang, Malay, 1800ft \\
\hline
\end{tabular}

$\dagger$ NHM, the Natural History Museum (London, UK); NMNH, the National Museum of Natural History (Washington DC, USA); LKCNHM, the Lee Kong Chian Natural History Museum (Singapore). 
Appendix 2. Landmarks used in this study.

\begin{tabular}{ll}
\hline Landmark & Definition \\
\hline 1 & Prosthion: antero-inferior point on projection of pre-maxilla between central incisors \\
2 & Leftside zygo-temp inferior: infero-lateral point of zygomaticotemporal suture on lateral face of zygon \\
3 & Rightside zygo-temp inferior: infero-lateral point of zygomaticotemporal suture on lateral face of zygom \\
4 & Lambda: junction of sagittal and lamboid sutures \\
5 & Bregma: junction of coronal and sagittal sutures \\
6 & Leftside frontomalare temporale: where frontozygomatic suture crosses lateral edge of zygoma \\
7 & Rightside frontomalare temporale: where frontozygomatic suture crosses lateral edge of zygoma \\
8 & Leftside frontomalare orbitale: where frontozygomatic suture crosses inner orbital rim \\
9 & Rightside frontomalare orbitale: where frontozygomatic suture crosses inner orbital rim \\
10 & Leftside supraorbital notch \\
11 & Rightside supraorbital notch \\
12 & Leftside meeting point of frontal, nasal, and lacrimal \\
13 & Rightside meeting point of frontal, nasal, and lacrimal \\
14 & Leftside zygo-max superior: antero-superior point of zygomaticomaxillary suture taken at orbit rim \\
15 & Rightside zygo-max superior: antero-superior point of zygomaticomaxillary suture taken at orbit rim \\
16 & Nasion: midline point on fronto-nasal suture \\
17 & Rhinion: most anterior midline point on nasals \\
18 & Rightside most lateral meeting point of mastoid part of temporal bone and occipital \\
19 & Leftside most lateral meeting point of mastoid part of temporal bone and occipital \\
20 & Rightside meeting point of mastoid, occipital and petrosal \\
21 & Leftside meeting point of mastoid, occipital and petrosal \\
22 & Rightside meeting point between sphenoid, occipital and petrosal
\end{tabular}


Leftside meeting point between sphenoid, occipital and petrosal

Rightside most medial point of medial pterygoid fossa

Leftside most medial point of medial pterygoid fossa

Rightside meeting point of petrous part of temporal bone, alisphenoid and base of zygomatic process of temporal bone

Leftside meeting point of petrous part of temporal bone, alisphenoid and base of zygomatic process of temporal bone

Rightside zygo-max inferior: antero-inferior point of zygomaticomaxillary suture

Leftside zygo-max inferior: antero-inferior point of zygomaticomaxillary suture

Rightside M3 distal midpoint projected (laterally) onto alveolar margin

Leftside M3 distal midpoint projected (laterally) onto alveolar margin

Tip of posterior nasal spine

Rightside anterior-most point of canine alveolus

Leftside anterior-most point of canine alveolus

Leftside most posterior tip of occlusal surface of M3

Leftside most posterior tip of occlusal surface of M2

Leftside most posterior tip of occlusal surface of M1

Leftside most posterior tip of occlusal surface of P4

Leftside most posterior tip of occlusal surface of P3

Leftside most anterior tip of occlusal surface of P3

Rightside most posterior tip of occlusal surface of M3

Rightside most posterior tip of occlusal surface of M2

Rightside most posterior tip of occlusal surface of M1

Rightside most posterior tip of occlusal surface of P4

Rightside most posterior tip of occlusal surface of P3

Rightside most anterior tip of occlusal surface of P3 
$47 \quad$ Rightside condylion

$48 \quad$ Leftside condylion

49 Rightside most medial point of mandible condyle

50 Leftside most medial point of mandible condyle

51 Rightside most inferior point of mandibular notch

52 Leftside most inferior point of mandibular notch

53 Rightside Coronion

$54 \quad$ Leftside Coronion

55 Rightside most posterior point on the ascending ramus in line with the alveolus

56 Leftside most anterior point on the ascending ramus in line with the alveolus

$57 \quad$ Rightside Gonion

$58 \quad$ Leftside Gonion

$59 \quad$ Rightside most anterior insertion of digastric

$60 \quad$ Leftside most anterior insertion of digastric

$61 \quad$ Gnathion

62 Rightside most anterior point on the ascending ramus in line with the alveolus

63 Leftside most anterior point on the ascending ramus in line with the alveolus

64 Ligunal-side most superior point of mandibular symphysis

$65 \quad$ Rightside most posterior point of canine alveolus

$66 \quad$ Leftside most posterior point of canine alveolus

$67 \quad$ Symphysion 
Appendix 3. Model selection table.

\begin{tabular}{|c|c|c|c|c|c|c|}
\hline Intercept & Size & Latitude & $\begin{array}{l}\text { Region } \\
\text { (south vs. } \\
\text { north of } \\
\text { IOK) }\end{array}$ & $\begin{array}{l}\text { Annual } \\
\text { mean } \\
\text { temperatur } \\
\mathrm{e}\end{array}$ & $\begin{array}{l}\text { Annual } \\
\text { precipitati } \\
\text { on }\end{array}$ & $\Delta \mathrm{AIC}$ \\
\hline \multicolumn{7}{|l|}{ PC4 } \\
\hline 0.12 & & & 0.34 & & & 0.00 \\
\hline 0.12 & & 0.14 & 0.45 & & & 1.36 \\
\hline 0.12 & -0.04 & & 0.34 & & & 1.85 \\
\hline 0.11 & & & 0.33 & 0.06 & & 1.88 \\
\hline 0.12 & & & 0.34 & & -0.04 & 1.89 \\
\hline 0.12 & -0.04 & 0.14 & 0.45 & & & 3.24 \\
\hline 0.11 & & 0.14 & 0.44 & 0.04 & & 3.31 \\
\hline 0.12 & & 0.14 & 0.45 & & -0.02 & 3.33 \\
\hline 0.11 & -0.04 & & 0.33 & 0.06 & & 3.71 \\
\hline 0.12 & -0.03 & & 0.34 & & -0.03 & 3.80 \\
\hline 0.11 & & & 0.33 & 0.05 & -0.03 & 3.82 \\
\hline \multicolumn{7}{|l|}{ PC8 } \\
\hline 0.02 & -0.24 & -0.54 & -0.54 & & & 0.00 \\
\hline 0.02 & & -0.52 & -0.53 & & & 1.30 \\
\hline 0.00 & -0.25 & -0.56 & -0.57 & 0.09 & & 1.83 \\
\hline 0.01 & -0.23 & -0.56 & -0.56 & & -0.05 & 1.91 \\
\hline 0.01 & -0.23 & & & & & 2.47 \\
\hline 0.01 & & -0.56 & -0.58 & & -0.13 & 2.64 \\
\hline 0.01 & & & & & & 3.10 \\
\hline 0.01 & & -0.53 & -0.55 & 0.06 & & 3.24 \\
\hline 0.01 & -0.24 & -0.12 & & & & 3.79 \\
\hline 0.01 & -0.22 & & -0.12 & & & 3.80 \\
\hline 0.00 & -0.24 & -0.56 & -0.57 & 0.08 & -0.03 & 3.80 \\
\hline 0.02 & & & -0.13 & & & 4.36 \\
\hline 0.01 & -0.24 & & & & 0.05 & 4.38 \\
\hline 0.01 & -0.23 & & & -0.04 & & 4.43 \\
\hline 0.01 & & -0.10 & & & & 4.61 \\
\hline 0.01 & & -0.56 & -0.58 & 0.01 & -0.13 & 4.64 \\
\hline
\end{tabular}

Models that have $\triangle \mathrm{AIC}<5$ are shown. 


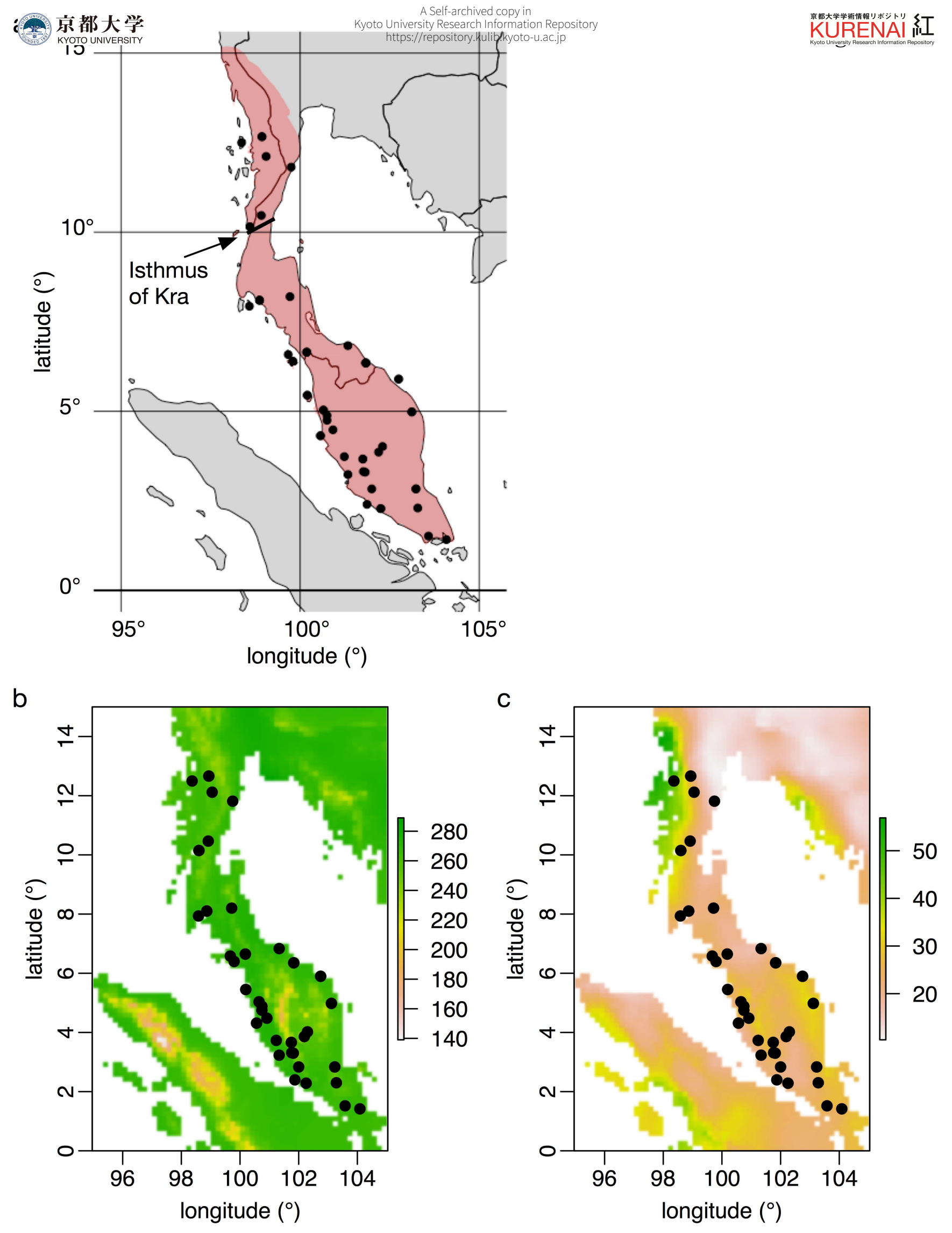



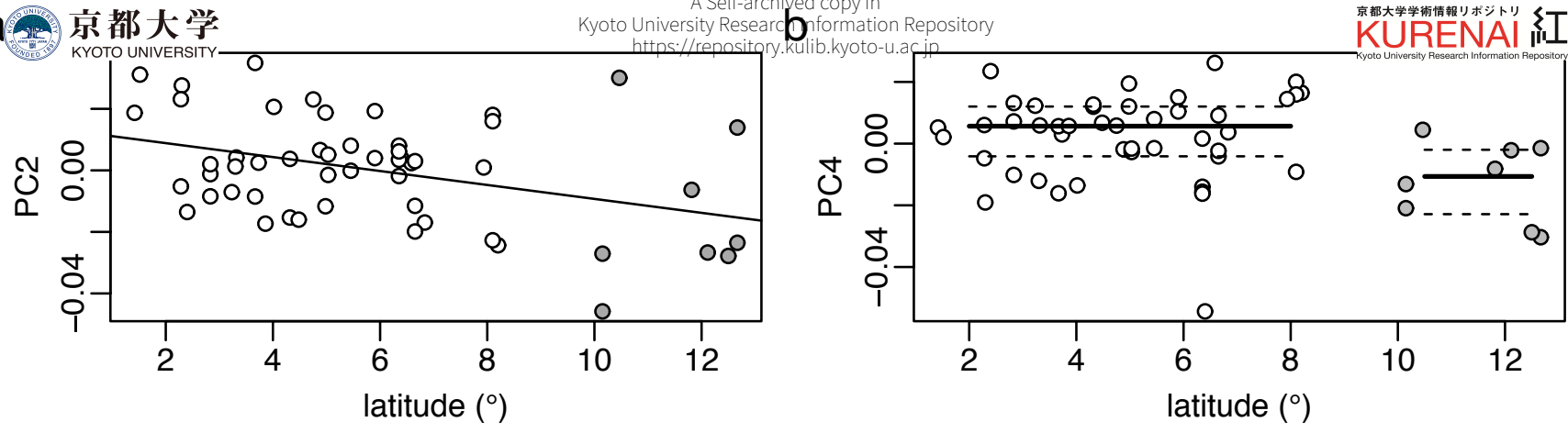

C

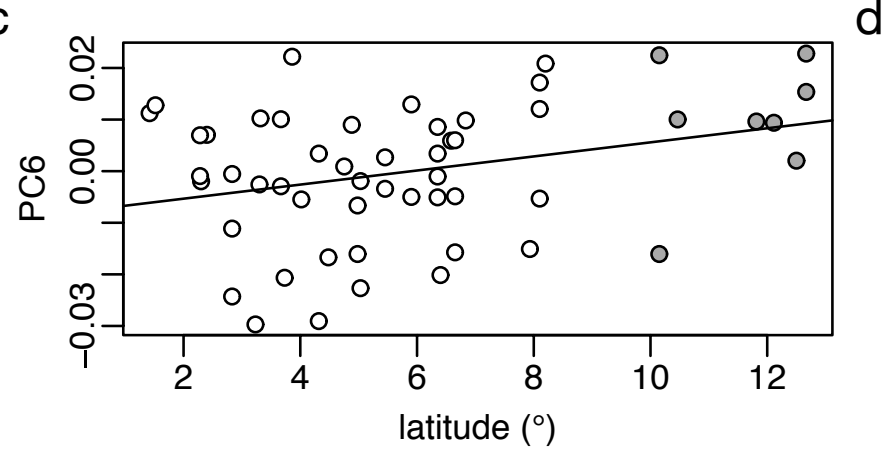

d

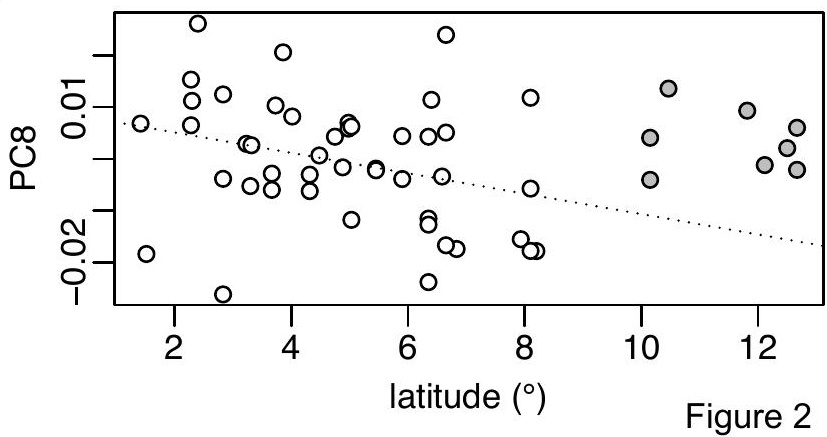



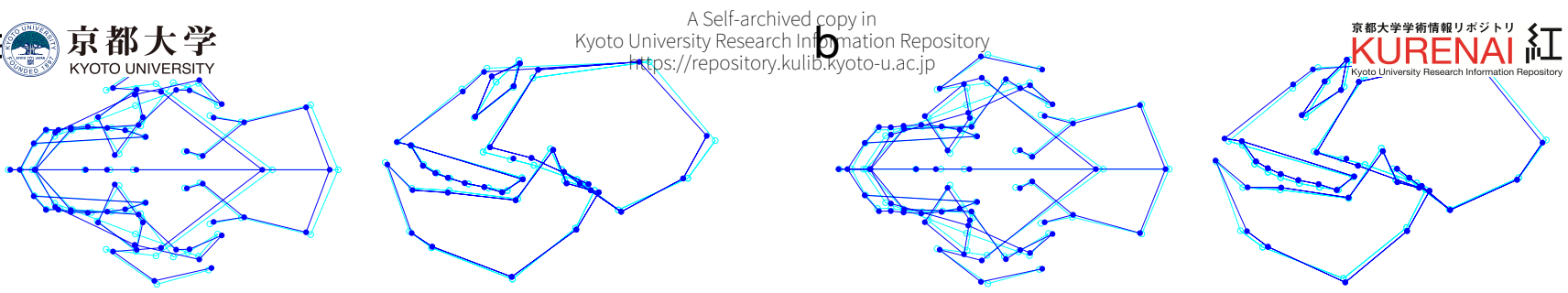

C
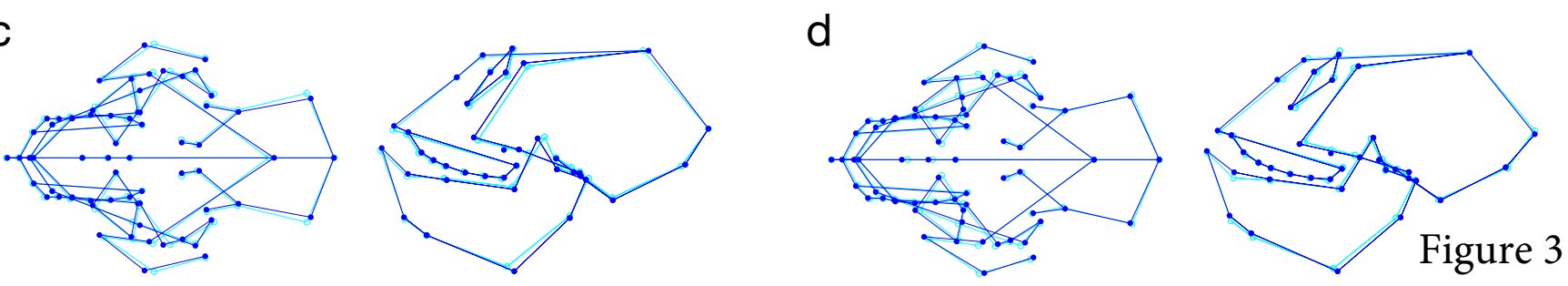


\section{¿ 0 京都大学}

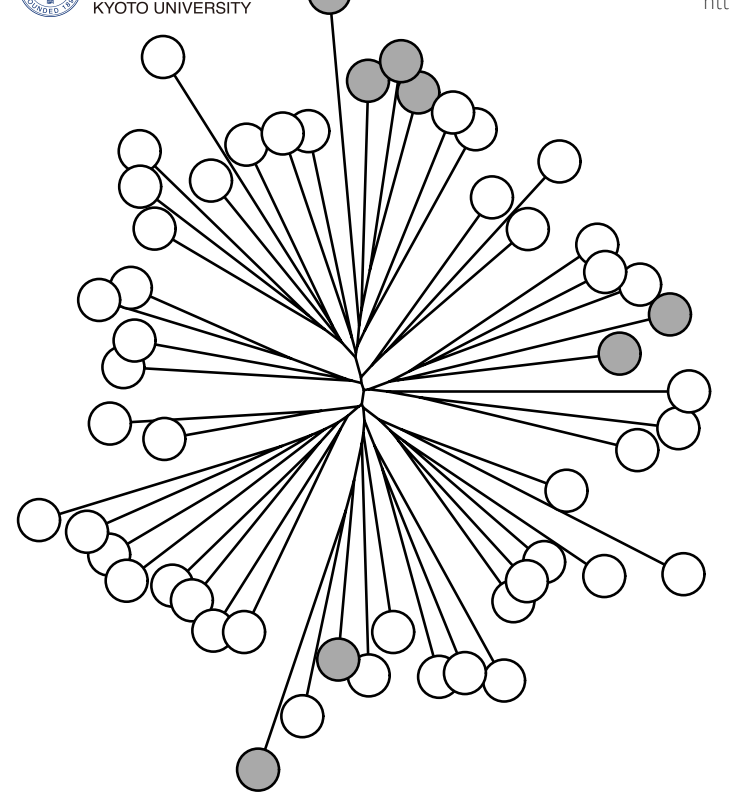

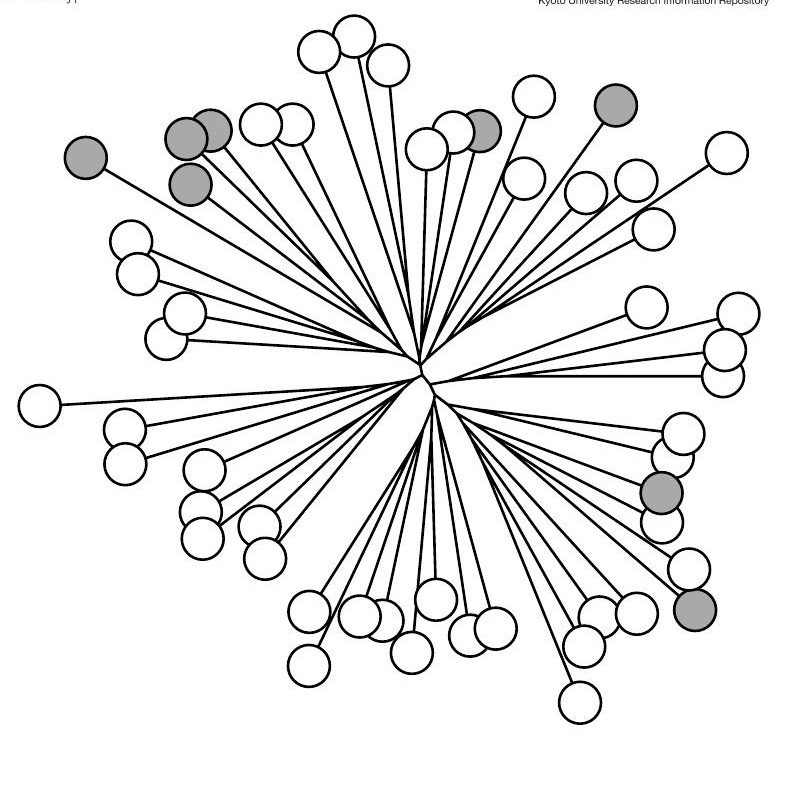

